\title{
Letter to the Editor: Metabolomics of Aqueous Humor in Diabetes Mellitus
}

\author{
Diana Anna Dmuchowska, Karolina Pietrowska, ${ }^{2}$ Pawel Krasnicki, ${ }^{1}$ \\ Emil Tomasz Grochowski, Zofia Mariak, ${ }^{1}$ Adam Kretowski, ${ }^{2,3}$ and Michal Ciborowski ${ }^{2}$
}

\section{Dear Editor:}

W E HAVE READ WITH GREAT interest the article by Wang et al. entitled "Metabolomic profile of diabetic retinopathy: a GC-TOFMS-based approach using vitreous and aqueous humor."1 The authors identified novel metabolites and disturbed metabolic pathways. This is not the first article presenting the metabolic profiles of aqueous humor $(\mathrm{AH})$, which are characteristic for diabetes mellitus. ${ }^{1-4}$ However, each of those studies identified different metabolic pathways as the most disturbed (Table 1), which might cause some confusion among the readers. We would like to explain these discrepancies and to demonstrate that they represent a characteristic feature of metabolomic studies, rather than a methodological error.

The significance of prevention, treatment, and slowing down the progression of diabetic complications raises no doubts in the context of reducing health and economic burden. From an ophthalmological perspective, diabetic retinopathy should be considered a potentially blinding disease. In our article, ${ }^{2}$ we emphasized that diabetes might accelerate cataract development and increase complication rates after cataract surgeries.

Metabolomic studies aim to identify the underlying mechanisms of disease. The composition of small molecules can be considered a chemical marker of a current phenotype.

Table 1. A Summary of the Methodology and Results of Previous Studies of Aqueous Humor Metabolic Composition in Diabetes Mellitus Patients

\begin{tabular}{|c|c|c|c|c|c|}
\hline \multirow[b]{2}{*}{ Reference } & \multirow[b]{2}{*}{$\begin{array}{l}\text { Analytical } \\
\text { method }\end{array}$} & \multirow[b]{2}{*}{$\begin{array}{c}\text { Study } \\
\text { participants }\end{array}$} & \multirow{2}{*}{$\begin{array}{c}\text { Number of detected and distinctive } \\
\text { to DM metabolic features } \\
\text { or metabolites }\end{array}$} & \multicolumn{2}{|r|}{$\begin{array}{l}\text { Disturbed metabolic } \\
\text { pathways distinctive to DM }\end{array}$} \\
\hline & & & & Count & $\begin{array}{l}\text { The names of the most } \\
\text { relevant pathways }\end{array}$ \\
\hline 1 & GC-TOFMS & $\begin{array}{l}23 \text { PDR, } \\
25 \text { controls }\end{array}$ & $\begin{array}{l}\text { 200-detected metabolic features } \\
\text { 137-detected metabolites } \\
8 \text {-metabolites distinctive to DM }\end{array}$ & 3 & $\begin{array}{l}\text { Glycolysis or gluconeogenesis } \\
\text { Galactose metabolism } \\
\text { Ascorbate-aldarate metabolism }\end{array}$ \\
\hline 2 & LC-MS & $\begin{array}{l}16 \mathrm{DM} \text {, } \\
19 \text { controls }\end{array}$ & $\begin{array}{l}1222 \text { - detected metabolic features } \\
125 \text { - metabolic features distinctive } \\
\text { to DM } \\
\text { 29-metabolites distinctive to DM }\end{array}$ & 13 & $\begin{array}{l}\text { D-Arginine and D-ornithine } \\
\text { metabolism } \\
\text { One carbon pool by folate } \\
\text { Arginine and proline metabolism } \\
\text { Purine metabolism } \\
\text { Taurine and hypotaurine } \\
\text { metabolism }\end{array}$ \\
\hline 3 & ${ }^{1} \mathrm{H}-\mathrm{NMR}$ & $\begin{array}{l}13 \mathrm{DR}, 14 \mathrm{DM} \text {, } \\
7 \text { controls }\end{array}$ & $\begin{array}{l}\text { 26- detected metabolites } \\
10 \text { - metabolites distinctive to DM }\end{array}$ & 11 & $\begin{array}{l}\text { Alanine, aspartate, and } \\
\text { glutamate metabolism }\end{array}$ \\
\hline 4 & GC-TOFMS & $\begin{array}{l}15 \mathrm{DM}, \\
15 \text { controls }\end{array}$ & $\begin{array}{l}263 \text { - detected metabolites } \\
20 \text { - metabolites distinctive to DM }\end{array}$ & 10 & $\begin{array}{l}\text { Fatty acid biosynthesis } \\
\text { Fatty acid metabolism } \\
\text { Linoleic acid metabolism }\end{array}$ \\
\hline
\end{tabular}

DM, diabetes mellitus; DR, diabetic retinopathy; GC-TOFMS, gas chromatography coupled with time-of-flight mass spectrometry; ${ }^{1} \mathrm{H}-\mathrm{NMR}$, proton nuclear magnetic resonance spectroscopy; LC-MS, liquid chromatography-mass spectrometry; PDR, proliferative diabetic retinopathy.

Departments of ${ }^{1}$ Ophthalmology and ${ }^{3}$ Endocrinology, Diabetology and Internal Medicine, Medical University of Bialystok, Bialystok, Poland.

${ }^{2}$ Clinical Research Centre, Medical University of Bialystok, Bialystok, Poland.

(C) Diana Anna Dmuchowska et al. 2020; Published by Mary Ann Liebert, Inc. This Open Access article is distributed under the terms of the Creative Commons Attribution Noncommercial License (http://creativecommons.org/licenses/by-nc/4.0/) which permits any noncommercial use, distribution, and reproduction in any medium, provided the original author(s) and the source are cited. 
In diabetes, metabolomic studies involved a plethora of body fluids, among them serum, vitreous humor, and $\mathrm{AH}$. Similar to Wang et al., ${ }^{1}$ this is AH, which represents our primary interest.

As mentioned earlier, a total of four untargeted metabolomic studies of $\mathrm{AH}$ in diabetic patients have been indexed in PubMed on July 10, 2020. ${ }^{1-4}$ We were the first to report the differences in $\mathrm{AH}$ composition in diabetic and nondiabetic patients. ${ }^{2}$ There are various analytical platforms that could be used in metabolomic studies. The most commonly used methods include nuclear magnetic resonance or mass spectrometry (MS), coupled with various separation techniques: liquid chromatography (LC)-MS, gas chromatography (GC)-MS, and capillary electrophoresis (CE)-MS. Importantly, each of those methods is suitable for the detection of different metabolite classes. For example, GCMS is the best method to detect volatile metabolites or the metabolites, which can be transformed into volatile derivatives. Meanwhile, LC-MS is more suitable for nonpolar or medium polar metabolites, and CE-MS for highly polar metabolites. Furthermore, even using the same analytical method, different metabolite classes could be detected depending on the sample preparation procedure. This is demonstrated in Table 1, comparing the results of two studies that used the same GC-MS approach, but with different extraction protocols. ${ }^{1-4}$ In conclusion, specific methods are more suitable for the detection of particular metabolites. It also needs to be stressed that none of these methods could provide information about the entire metabolome. This seems to be a primary reason behind the discrepancies in the results of published metabolomic studies of $\mathrm{AH}$ in diabetes.

In summary, metabolomics has the potential to detect altered metabolic pathways and to identify novel biomarkers. However, various techniques provide complementary results rather than equivalent ones, and hence, the metabolomic studies of $\mathrm{AH}$ and other biofluids should involve a multiplatform approach. This will allow us to detect a broader spectrum of metabolites, providing a better insight into the problem in question.

\section{References}

1. Wang, H., Fang, J., Chen, F., et al. Metabolomic profile of diabetic retinopathy: a GC-TOFMS-based approach using vitreous and aqueous humor. Acta Diabetol. 57:41-51, 2020.

2. Pietrowska, K., Dmuchowska, D.A., Krasnicki, P., et al. An exploratory LC-MS-based metabolomics study reveals differences in aqueous humor composition between diabetic and non-diabetic patients with cataract. Electrophoresis. 39: 1233-1240, 2018.

3. Jin, H., Zhu, B., Liu, X., Jin, J., and Zou, H. Metabolic characterization of diabetic retinopathy: an ${ }^{1} \mathrm{H}-\mathrm{NMR}$-based metabolomic approach using human aqueous humor. J. Pharm. Biomed. Anal. 174:414-421, 2019.

4. Yao, Y., Wang, H., Zhu, B., et al. Aqueous humor metabolomic profiles in association with diabetic mellitus. Int. J. Clin. Exp. Pathol. 11:3479-3486, 2018.

Received: July 13, 2020 Accepted: July 15, 2020

Address correspondence to: Dr. Diana Anna Dmuchowska Department of Ophthalmology Medical University of Bialystok 24a M. Sklodowskiej-Curie Street Bialystok 15-276

Poland

E-mail: diana.dmuchowska@umb.edu.pl 